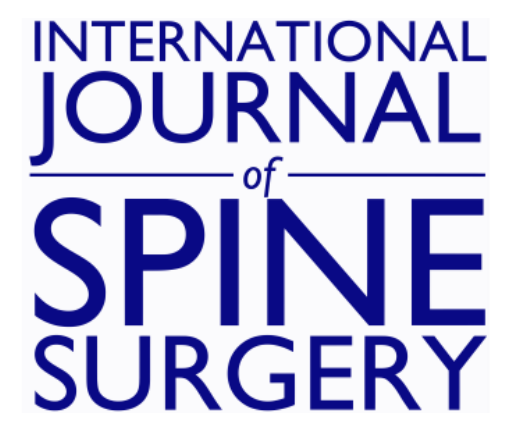

\title{
Clinical values of control over pain and pain coping strategies in surgical treatment for patients with lumbar spinal stenosis
}

Daisuke Higuchi

Int J Spine Surg 2016, 10 ()

doi: https://doi.org/10.14444/3022

http://ijssurgery.com/content/10/22

This information is current as of April 26, 2023.

Email Alerts Receive free email-alerts when new articles cite this article. Sign up at:

http://ijssurgery.com/alerts

The International Journal of Soine Surgerh 2397 Waterbury Circle, Suite 1,

Aurora, IL 60504, Phone: +1-630-375-1432

(C) 2016 ISASS. All Rights Reserved. 


\section{Clinical values of control over pain and pain coping strategies in surgical treatment for patients with lumbar spinal stenosis}

Daisuke Higuchi, DHSc. ${ }^{1,2}$

${ }^{1}$ Department of Physical Therapy, Faculty of Health Care, Takasaki University of Health and Welfare, Tasakaki, Gunma, Japan ${ }^{2}$ Department of Rehabilitation, Harunaso Hospital, Tasakaki, Gunma, Japan

\section{Abstract}

\section{Background}

Control over pain and pain coping strategies are associated with pain intensity as well as psychological status and subjective disability in patients experiencing pain. The present study assessed the clinical values of control over pain and pain coping strategies in surgical treatment for patients with lumbar spinal stenosis using mediation analysis.

\section{Methods}

Sixty-two patients with lumbar spinal stenosis (median age, 70 years; 34 men, 28 women) were evaluated before surgery. The pain intensity and area, psychological status/subjective disability (Japanese Orthopaedic Association Back Pain Evaluation Questionnaire), and control over pain/pain coping strategies (Coping Strategies Questionnaire) were assessed. Mediation analysis, which consisted of serial regression analyses, mainly tested whether (1) control over pain/pain coping strategies were predicted by pain characteristics and (2) control over pain/pain coping strategies predicted psychological status/subjective disability after controlling for pain characteristics.

\section{Results}

Control over pain was predicted by pain intensity (regression coefficient, $-0.33 ; \mathrm{p}=0.01$ ); moreover, it predicted walking ability (standardized partial regression coefficient, $0.31 ; \mathrm{p}=0.01)$ and social function $(0.38 ; \mathrm{p}=0.00)$ after controlling for pain intensity. Although increasing activity level, one pain coping strategy, was predicted by pain intensity (regression coefficient, $-0.30 ; \mathrm{p}=0.02$ ), it did not predict walking ability (standardized partial regression coefficient, $0.07 ; \mathrm{p}=0.53)$ or social function $(0.13 ; \mathrm{p}=0.33)$ when considering pain intensity.

\section{Conclusions}

In this cohort, mediation analysis demonstrated that pain intensity did not directly affect perceived walking ability or social function, but did affect control over pain; moreover, control over pain affected walking ability and social function.

\section{Clinical relevance}

These findings are useful for a deep understanding of the relationships between pain and subjective disability in preoperative patients with lumbar spinal stenosis. More attention should be given to patients' thoughts about pain such as control over pain.

KEYWORDS: LUMBAR SPINAL STENOSIS, CONTROL OVER PAIN, PAIN COPING STRATEGIES, MEDIATION

\section{Introduction}

Patients with lumbar spinal stenosis (LSS) often have neuropathic leg pain due to nerve root compression and/or cauda equine syndrome. Therefore, management of neuropathic pain is important in patients with LSS.
Correlations of pain intensity with psychological status and subjective disability have been demonstrated in patients with LSS. ${ }^{1}$ According to previous research, the more severe the pain intensity, the worse the psychological status and subjective disability in patients with LSS. ${ }^{1}$ In the clinical setting, however, we encounter patients with LSS who do not have much deterioration of their psychological status and/ 
or subjective disability relative to severe pain and vice versa.

The transactional model of stress ${ }^{2}$ can explain this clinical anomaly. This transactional model emphasizes the following two points: 1) causes of stress (e.g., pain) do not directly affect stress reactions (e.g., psychological status); and 2) cognitive appraisals "mediate" between causes of stress and stress reactions and can modify stress reactions. Pain-related beliefs (e.g., perceived control over pain) and pain coping strategies, which are the behaviors and thoughts patients use to cope with pain, were cognitive appraisals in patients experiencing pain. Control over pain and pain coping strategies are reportedly associated with pain intensity ${ }^{3}$ as well as psychological status and subjective disability ${ }^{3-5}$ in painful patients. Based on these findings, the present author hypothesized that control over pain and pain coping strategies "mediate" between pain and psychological status/subjective disability in painful patients with LSS. However, this model has not yet been established and is therefore unpopular in patients with LSS.

Mediation analysis was developed to investigate whether a factor mediates between a cause and a result. This analysis is used for a population of painful patients. ${ }^{6}$ Kim et al. ${ }^{7}$ reported that pain catastrophizing, a cognitive appraisal for pain, mediated between sex differences in pain and subjective disability in patients with LSS. Mediation analysis is a suitable statistical technique for testing the abovementioned hypothesis including control over pain and pain coping strategies.

The present study assessed the clinical values of control over pain and pain coping strategies in surgical treatment for patients with LSS. This assessment involved a mediation analysis to test whether control over pain and pain coping strategies mediated between pain and psychological status/subjective disability in preoperative patients with LSS.

\section{Materials and Methods}

Study design

This cross-sectional study was conducted from Octo- ber 2011 to January 2014 in a Japanese general hospital with a spine care center. The study was performed after gaining approval from the ethics committee of the hospital.

\section{Participants}

Preoperative patients with LSS who had neuropathic leg pain participated. Decompressive surgery with/ without spinal fusion was planned for all patients. In all patients, imaging such as magnetic resonance imaging or computed tomography was used to confirm that nerve root(s) or dura mater were pressed by osseous and/or soft tissues, and leg pain was temporarily relieved by root block or continuous epidural anesthesia before proposal for surgery. Surgery was avoided for patients whose pain was obviously derived from other factors such as hip or knee osteoarthritis, diabetes mellitus, deep vein thrombosis, or tarsal tunnel syndrome.

The following preoperative patients were excluded from the present study: those with a history of lumbar surgery, those who needed major spinal reconstruction at three or more levels, those who had a psychiatric history, and those whose cognitive function was so low that they could not explain their pain in detail.

\section{Assessments}

Pain characteristics

An 11-point numerical rating scale (NRS) $(0=$ no pain, $10=$ unbearable pain) and a pain drawing test were used to assess the intensity and area of leg pain, respectively. Patients were asked about their average intensity and area of pain experienced during activities of daily living. Ohlund's method $(0=$ no pain, $111=$ whole-body pain $)^{8}$ was applied to quantify the results of the pain drawing test.

Psychological status and subjective disability

The Japanese Orthopaedic Association Back Pain Evaluation Questionnaire (JOABPEQ), ${ }^{9}$ the test-retest reliability and construct validity of which have been assessed, ${ }^{10,11}$ is classified into the following five subcategories: mental health, walking ability, social function, low back pain, and lumbar function. Subcategories of mental health and walking ability/ social function were used to assess patients' psycho- 
logical status and subjective disability, respectively. Each subcategory score was calculated by an established formula (0-100 points, where $0=$ poor psychological status or severe subjective disability).

Control over pain and pain coping strategies

The Japanese short version of the Coping Strategies Questionnaire (CSQ-J), ${ }^{12}$ which is based on the original CSQ ${ }^{13}$ was used. Internal reliability of the CSQ has been ensured, ${ }^{14}$ and its construct validity is generally acceptable. ${ }^{15}$ Both the CSQ and the CSQ-J assess control over pain and include six cognitive strategies (praying or hoping, catastrophizing, coping self-statements, diverting attention, reinterpreting pain sensations, and ignoring pain sensations) and two behavioral strategies (increasing pain behavior and increasing activity level). The CSQ-J contains one question for control over pain and two questions for each cognitive and behavioral strategy. In the present study, these questions were graded on a sevenpoint Likert scale $(0=$ "no control over pain" or "never do" and 6 = "complete control over pain" or "always do that when in pain"). Thus, the score for control over pain ranged from 0 to 6 points, and the score for each coping strategy ranged from 0 to 12 points. Greater scores indicated that patients either could control their pain more effectively or more frequently used the coping strategy.

\section{Statistical methods}

The median and quartile deviation (QD) as well as the maximum and minimum values were calculated as the representative value of each assessed item.

Pain characteristics (NRS score and pain drawing test result) were defined as "variables A," control over pain and pain coping strategies (CSQ-J subcategory scores) were defined as "variables B," and psychological status and subjective disability (JOABPEQ subcategory scores for mental health, walking ability, and social function) were defined as "variables C."

The present hypothetical "mediation" model (Figure 1) was investigated by the following three-step regression models, collectively termed mediation analysis (Figure 2):
First regression model: Variables A were used as independent variables, and variables $C$ were used as dependent variables. If the mediation model was concluded, significant regression coefficients of variables A had to be obtained.

Second regression model: Variables A were used as independent variables, and variables $B$ were used as

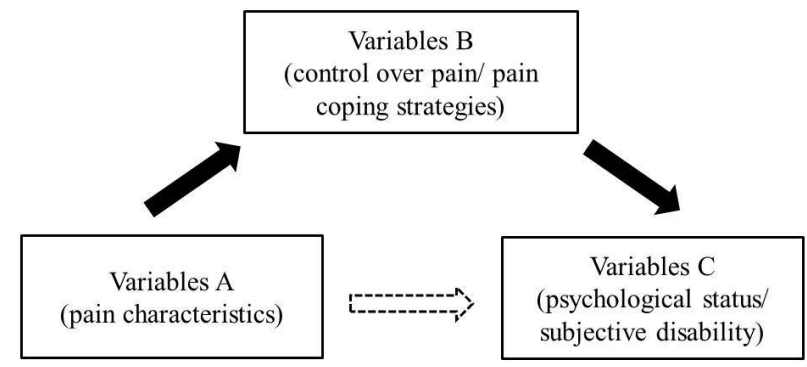

Fig. 1. Hypothetical mediation model. We supposed that variables $A$ affected variables $C$ through variables $B$ (black arrows), and so the direct impact of variables $A$ on variables $C$ was weak or spurious (dotted white arrow).

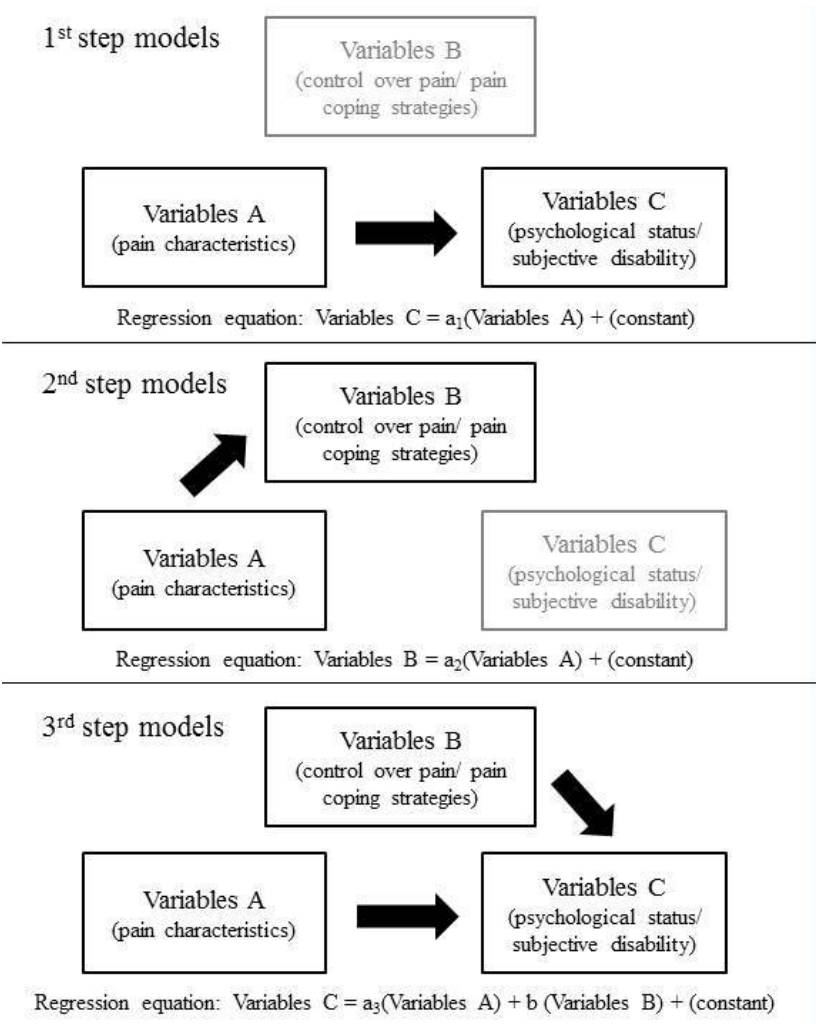

Fig. 2. Three-step regression models in mediation analysis. The first-step models were constructed to predict variables $C$ using variables $A$. The second-step models were constructed to predict variables $B$ using variables $A$. The third-step models were constructed to predict variables $C$ using both variables $A$ and $B$. When variables $A$ affected variables $C$ via variables $B$, the standardized regression coefficients of variables $A$ for variables $C$ in the third-step models had to be lower than the regression coefficients of variables $\mathrm{A}$ for variables $\mathrm{C}$ in the first-step models. 
dependent variables. If the mediation model was concluded, significant regression coefficients of variables B had to be obtained.

Third regression model: Both variables $\mathrm{A}$ and $\mathrm{B}$ were used as independent variables, and variables $C$ were used as dependent variables. If the mediation model was concluded, significant standardized partial regression coefficients of variables B had to be obtained, and standardized partial regression coefficients of variables A had to be lower than those in the first regression model.

Finally, the nonparametric bias-corrected bootstrap method $(n=2000)$ was performed to check whether the indirect effects of variables $A$ for variables $C$ via variables $B$ were statistically significant.

All statistical analyses were performed using HAD ver. 13 developed by Yuji Shimizu of Kwansei Gakuin University, Japan. ${ }^{16}$ Values of $\mathrm{p}<0.05$ were considered statistically significant.

\section{Results}

Sixty-two patients with LSS (34 men, 28 women) participated in the present study. The patients' age ranged from 45 to 82 years (median, 70 years; QD, 4.5 years). Thirty-three of 62 patients (53.2\%) were diagnosed with LSS with spondylolisthesis, six patients $(9.7 \%)$ were diagnosed with LSS with degenerative scoliosis, and three patients (9.4\%) were diagnosed with LSS with spondylolisthesis and degenerative scoliosis. The symptom duration ranged from $<1$ to 10 years (median, 2 years; QD, 1.5 years). No patients had a symptom duration of $>10$ years.

The median, QD, and range of each assessed item are summarized in Table 1.

The NRS score predicted the walking ability and social function scores, but the pain drawing test result was not predictive in the first regression model (upper part of Table 2). Therefore, only the NRS score was used as an independent variable in the next second regression model.

The NRS score predicted the control over pain and increasing activity level scores in the second regression model (lower part of Table 2). Thus, the following four combinations were tested in the next third regression model. Combination 1: The NRS score and control over pain were used as independent variables, and walking ability was used as a dependent variable. Combination 2: The NRS score and control over pain were used as independent variables, and social function was used as a dependent variable. Combination 3: The NRS score and increasing activity level were used as independent variables, and walking ability was used as a dependent variable. Combination 4: The NRS score and increasing activity level were used as independent variables, and social function was used as a dependent variable.

\begin{tabular}{|c|c|c|c|c|}
\hline Items (range of scores) & Median & $\begin{array}{r}\text { Quartile } \\
\text { deviation }\end{array}$ & Maximum & Minimum \\
\hline \multicolumn{5}{|l|}{ Pain characteristics } \\
\hline $\begin{array}{l}\text { Numerical rating scale } \\
(0-10)\end{array}$ & 7 & 2.0 & 2 & 10 \\
\hline Pain drawing $(0-111)$ & 19.5 & 6.6 & 70 & 1 \\
\hline \multicolumn{5}{|l|}{$\begin{array}{l}\text { Psychological status and } \\
\text { subjective disability }\end{array}$} \\
\hline Mental health $(0-100)$ & 47.6 & 8.5 & 74.8 & 2.9 \\
\hline Walking ability $(0-100)$ & 28.6 & 14.3 & 100 & 0 \\
\hline Social function $(0-100)$ & 45.9 & 9.5 & 86.5 & 0 \\
\hline \multicolumn{5}{|l|}{$\begin{array}{l}\text { Control over pain and pain } \\
\text { coping strategies }\end{array}$} \\
\hline Control over pain $(0-6)$ & 3 & 0.5 & 0 & 5 \\
\hline Praying or hoping $(0-12)$ & 12 & 2.4 & 2 & 12 \\
\hline Catastrophizing $(0-12)$ & 6 & 2.4 & 0 & 11 \\
\hline $\begin{array}{l}\text { Coping self-statements } \\
(0-12)\end{array}$ & 9 & 3.0 & 2 & 12 \\
\hline Diverting attention $(0-12)$ & 8 & 2.0 & 0 & 12 \\
\hline $\begin{array}{l}\text { Reinterpreting pain sensa- } \\
\text { tions }(0-12)\end{array}$ & 5 & 1.5 & 0 & 12 \\
\hline $\begin{array}{l}\text { Ignoring pain sensations } \\
(0-12)\end{array}$ & 5 & 2.0 & 0 & 12 \\
\hline $\begin{array}{l}\text { Increasing pain behavior } \\
(0-12)\end{array}$ & 8 & 2.0 & 0 & 12 \\
\hline $\begin{array}{l}\text { Increasing activity level } \\
(0-12)\end{array}$ & 6.5 & 2.0 & 0 & 12 \\
\hline
\end{tabular}


Standardized partial regression coefficients in the third multiple regression models are shown in Table 3. Indirect effects from pain intensity to walking ability/social function via control over pain (Combinations 1 and 2) were statistically significant.

Moreover, catastrophizing in addition to the NRS score was used as an independent variable for multiple regression analyses because catastrophizing predicted mental health (regression coefficient, $-0.41 ; \mathrm{p}$ $=0.00)$ and walking ability $(-0.30 ; p=0.02)$. As a result, catastrophizing predicted psychological status (standardized partial regression coefficient, $-0.39 ; \mathrm{p}$ $=0.00)$ and walking ability $(-0.26 ; \mathrm{p}=0.03)$ after controlling for the NRS score.

\begin{tabular}{|c|c|c|c|}
\hline Steps & $\begin{array}{l}\text { Independent } \\
\text { variables }\end{array}$ & $\begin{array}{l}\text { Dependent } \\
\text { variables }\end{array}$ & $\begin{array}{l}\text { Regression } \\
\text { coefficients }\end{array}$ \\
\hline \multirow[t]{6}{*}{$\begin{array}{l}\text { First regression } \\
\text { modellings }\end{array}$} & $\begin{array}{l}\text { Numerical } \\
\text { rating scale }\end{array}$ & \multirow{2}{*}{ Mental health } & $\begin{array}{l}-0.19(\mathrm{p}= \\
0.13)\end{array}$ \\
\hline & Pain drawing & & $\begin{array}{l}-0.11(\mathrm{p}= \\
0.42)\end{array}$ \\
\hline & $\begin{array}{l}\text { Numerical } \\
\text { rating scale }\end{array}$ & \multirow{2}{*}{ Walking ability } & $\begin{array}{l}-0.35(\mathrm{p}= \\
0.00)\end{array}$ \\
\hline & Pain drawing & & $\begin{array}{l}-0.12(\mathrm{p}= \\
0.35)\end{array}$ \\
\hline & $\begin{array}{l}\text { Numerical } \\
\text { rating scale }\end{array}$ & \multirow{2}{*}{ Social function } & $\begin{array}{l}-0.26(\mathrm{p}= \\
0.04)\end{array}$ \\
\hline & Pain drawing & & $\begin{array}{l}-0.15(\mathrm{p}= \\
0.25)\end{array}$ \\
\hline \multirow[t]{9}{*}{$\begin{array}{l}\text { Second regression } \\
\text { modellings }\end{array}$} & \multirow{9}{*}{$\begin{array}{l}\text { Numerical } \\
\text { rating scale }\end{array}$} & Control over pain & $\begin{array}{l}-0.33(\mathrm{p}= \\
0.01)\end{array}$ \\
\hline & & Praying or hoping & $0.07(p=0.60)$ \\
\hline & & Catastrophizing & $0.10(\mathrm{p}=0.44)$ \\
\hline & & $\begin{array}{l}\text { Coping } \\
\text { self-statements }\end{array}$ & $\begin{array}{l}-0.10(\mathrm{p}= \\
0.44)\end{array}$ \\
\hline & & Diverting attention & $\begin{array}{l}-0.21(\mathrm{p}= \\
0.10)\end{array}$ \\
\hline & & $\begin{array}{l}\text { Reinterpreting pain } \\
\text { sensations }\end{array}$ & $\begin{array}{l}-0.07(\mathrm{p}= \\
0.61)\end{array}$ \\
\hline & & $\begin{array}{l}\text { Ignoring pain } \\
\text { sensations }\end{array}$ & $\begin{array}{l}-0.24(\mathrm{p}= \\
0.06)\end{array}$ \\
\hline & & $\begin{array}{l}\text { Increasing pain } \\
\text { behavior }\end{array}$ & $0.23(\mathrm{p}=0.07)$ \\
\hline & & $\begin{array}{l}\text { Increasing activity } \\
\text { level }\end{array}$ & $\begin{array}{l}-0.30(\mathrm{p}= \\
0.02)\end{array}$ \\
\hline
\end{tabular}

$\mathrm{N}=62$

\section{Discussion}

Patient characteristics

The median NRS scores and the scores for mental health, walking ability, and social function of the JOABPEQ were 7.0, 47.6, 28.6, and 45.9 points, respectively, in the present study. Preoperatively, the patients had greater pain and lower walking ability than those in a large cohort studied by Ohtori et al. ${ }^{17}$ despite the fact that there were no large differences in demographic factors between the two cohorts. In addition, the present study included few patients whose symptom durations were 10 years, although the majority of patients in the present study had suffered from LSS for $<2$ years. However, it was thought that the patients in the present study were good surgical candidates because mechanical compression of the root(s) or dura mater based on osseous and/or soft tissues had been evident, and root block or continuous epidural anesthesia had been effective for pain relief.

Associations among pain characteristics, psychological status/subjective disability, and control over pain and pain coping strategies

The present study assessed whether control over pain and pain coping strategies mediate between pain

Table 3. Standardized partial regression coefficients in the third multiple regression model.

\begin{tabular}{|c|c|c|c|}
\hline Combinations & $\begin{array}{l}\text { Independent } \\
\text { variables }\end{array}$ & $\begin{array}{l}\text { Dependent } \\
\text { variables }\end{array}$ & $\begin{array}{l}\text { Standardized partial } \\
\text { regression coefficients }\end{array}$ \\
\hline \multirow[t]{2}{*}{1} & $\begin{array}{l}\text { Numerical } \\
\text { rating scale }\end{array}$ & \multirow{2}{*}{$\begin{array}{l}\text { Walking } \\
\text { ability }\end{array}$} & $-0.25(\mathrm{p}=0.04)$ \\
\hline & $\begin{array}{l}\text { Control over } \\
\text { pain }\end{array}$ & & $0.31(\mathrm{p}=0.01)$ \\
\hline \multirow[t]{2}{*}{2} & $\begin{array}{l}\text { Numerical } \\
\text { rating scale }\end{array}$ & \multirow{2}{*}{$\begin{array}{l}\text { Social } \\
\text { function }\end{array}$} & $-0.14(p=0.26)$ \\
\hline & $\begin{array}{l}\text { Control over } \\
\text { pain }\end{array}$ & & $0.38(\mathrm{p}=0.00)$ \\
\hline \multirow[t]{2}{*}{3} & $\begin{array}{l}\text { Numerical } \\
\text { rating scale }\end{array}$ & \multirow{2}{*}{$\begin{array}{l}\text { Walking } \\
\text { ability }\end{array}$} & $-0.24(p=0.60)$ \\
\hline & $\begin{array}{l}\text { Increasing } \\
\text { activity level }\end{array}$ & & $0.07(\mathrm{p}=0.53)$ \\
\hline \multirow[t]{2}{*}{4} & $\begin{array}{l}\text { Numerical } \\
\text { rating scale }\end{array}$ & \multirow{2}{*}{$\begin{array}{l}\text { Social } \\
\text { function }\end{array}$} & $-0.32(\mathrm{p}=0.02)$ \\
\hline & $\begin{array}{l}\text { Increasing } \\
\text { activity level }\end{array}$ & & $0.13(\mathrm{p}=0.33)$ \\
\hline
\end{tabular}

$N=62$. 
characteristics and psychological status/subjective disability using mediation analysis (Figure 1).

Combinations of the NRS score and walking function/social function passed the first regression model. The intensity of leg pain predicted walking ability and social functions, but the pain area did not predict mental health and subjective disability in the first regression model. In one study, the pain area was associated with anxiety in preoperative patients with cervical myelopathy. ${ }^{18}$ Patients with LSS often develop neuropathic leg pain that worsens upon standing and walking, while patients with cervical myelopathy experience continuous neuropathic pain in the distal limbs. The influences of the intensity and area of pain on mental health/subjective disability might be changeable according to the specificity of pain.

Control over pain and increasing activity level passed the second regression model. This is why the four combinations using the NRS score, walking function/social function, and control over pain/increasing activity level were established and tested by a third multiple regression model. The third regression model showed that control over pain predicted walking ability and social function after controlling for intensity of pain and that an increasing activity level did not predict subjective disability.

Paths from intensity of pain and walking ability/social function through control over pain were demonstrated by results of serial regression models and the post hoc bootstrap method. When considering these paths, the relationships between the intensity of pain and walking ability/social function became weak and spurious, respectively. The following relationships were highlighted: the greater the intensity of pain, the lower was the control over pain, and the lower the control over pain, the lower was the subjective walking ability and social function. These findings are consistent with previous research showing that increasing efficacy of control over pain is associated with a reduced intensity and frequency of pain. ${ }^{19}$ However, an increasing activity level did not predict walking ability and social function. The effects of this coping strategy on subjective disability were small compared with control over pain. Woby et al. ${ }^{20}$ reported that coping strategies were associated with pain intensity and subjective disability but that these relationships disappeared after controlling for control over pain. These findings suggest that how patients think about their pain is more important than how they behave in relation to their pain.

Catastrophizing predicted mental health and walking ability even if the influence of the intensity of pain on mental health and walking ability was accommodated. However, catastrophizing did not mediate between the intensity of pain and mental health/walking ability because catastrophizing was not related to the NRS score. Thus, we should understand that catastrophizing is an important factor that affects mental health and walking ability regardless of the intensity of pain.

In conclusion, the present study demonstrated that pain intensity affected control over pain, and control over pain in turn affected perceived walking ability and social function in patients with LSS who had neuropathic leg pain that was expected to be relieved through surgery. Furthermore, catastrophizing influenced mental health and walking ability, although catastrophizing did not mediate between intensity of pain and mental health/walking ability. These findings are useful for a deep understanding of the relationships between pain and subjective disability in preoperative patients with LSS. We should pay attention to patients' thoughts about pain, such as control over pain and catastrophizing, in surgical treatment for patients with LSS. Further studies are needed to determine whether the present mediation model of control over pain can be retained postoperatively. If this mediation model is useful both before and after surgery, the following postoperative course will be concluded in patients with LSS: a reduction in leg pain will lead to increasing control over pain, which will in turn lead to improved subjective disability. In other words, it is important to assess and increase control over pain after surgery.

\section{Study limitations}

There are three major limitations in the present study. First, the sample size was small, and the study was conducted in a single center. Therefore, supplementary examinations using other samples and settings are needed. Second, pain was assumed to be an 
independent variable and psychological status and subjective disability to be dependent variables based on the transactional model of stress. ${ }^{2} \mathrm{~A}$ crosssectional study cannot refer causality in a strict sense; thus, it cannot be excluded that psychological declines may have exacerbated the patients' pain. Previous studies have found that pain, depressive feelings, and subjective disability were improved by back surgery in patients with LSS. ${ }^{21,22}$ When a back surgery is performed to decrease pain but depressive feelings are not taken into account, it is reasonable to assume that the patient's improvement in depressive feelings was induced by an improvement in pain, at least in the early postoperative phase. Third, the use of only control over pain was not adequate to assess pain-related thoughts. It has been discussed that hope for relief from pain, ${ }^{23}$ self-efficacy, ${ }^{24}$ and a sense of coherence ${ }^{25}$ are cognitive factors associated with pain.

\section{Acknowledgments}

The author is grateful to the medical doctors and physical therapists at Harunaso Hospital for kindly providing support in the present study.

\section{References}

1. Kaptan H, Yalçın ES, Kasımcan O. Correlation of low back pain caused by lumbar spinal stenosis and depression in women: a clinical study. Arch Orthop Trauma Surg. 2012;132:7. 963-7. DOI: 10.1007/ s00402-012-1513-8.

2. Lazarus RS, Folkman S. Stress, Appraisal, and Coping. New York:Springer Publishing Company;1984.

3. Osborne TL, Jensen MP, Ehde DM, Hanley MA, Kraft G. Psychosocial factors associated with pain intensity, pain-related interference, and psychological functioning in persons with multiple sclerosis and pain. Pain. 2007;127:1-2. 52-62.

4. Turner JA, Dworkin SF, Mancl L, Huggins KH, Truelove EL. The roles of beliefs, catastrophizing, and coping in the functioning of patients with temporomandibular disorders. Pain. 2001;92:1-2. 41-51. 5. Raichle KA, Hanley M, Jensen MP, Cardenas DD. Cognitions, coping, and social environment pre- dict adjustment to pain in spinal cord injury. J Pain. 2007;8:9. 718-29.

6. Lee H, Hübscher M, Moseley GL, et al. How does pain lead to disability? A systematic review and meta-analysis of mediation studies in people with back and neck pain. Pain. 2015;156:6. 988-97. DOI: 10.1097/j.pain.0000000000000146.

7. Kim HJ, Cho CH, Kang KT, Chang BS, Lee CK, Yeom JS. The significance of pain catastrophizing in clinical manifestations of patients with lumbar spinal stenosis: mediation analysis with bootstrapping.

Spine J. 2015;15:2. 238-46. DOI: 10.1016/

j.spinee.2014.09.002.

8. Ohlund C, Eek C, Palmbald S, Areskoug B, Nachemson A. Quantified pain drawing in subacute low back pain. Validation in a nonselected outpatient industrial sample. Spine. 1996;21:9. 1021-31.

9. Fukui M, Chiba K, Kawakami M, et al. JOA Back Pain Evaluation Questionnaire (JOABPEQ)/JOA Cervical Myelopathy Evaluation Questionnaire (JOACMEQ). The report on the development of revised versions. J Orthop Sci. 2009;14:3. 348-65. DOI: $10.1007 / \mathrm{s} 00776-009-1337-8$.

10. Fukui M, Chiba K, Kawakami M, et al. Japanese Orthopaedic Association Back Pain Evaluation Questionnaire. Part 2. Verification of its reliability. J Orthop Sci. 2007;12:6. 526-32.

11. Fukui M, Chiba K, Kawakami M, et al. Japanese Orthopaedic Association Back Pain Evaluation Questionnaire. Part 3. Validity study and establishment of the measurement scale. J Orthop Sci. 2008;13:3. 173-9. DOI: 10.1007/s00776-008-1213-y.

12. Otake K, Shimai S. Pain experiences and coping strategies. Women's studies forum. 2002;16. 143-57 (in Japanese with English abstract).

13. Rosenetiel AK, Keefe FJ. The use of coping strategies in chronic low back pain patients: relationship to patient characteristics and current adjustment. Pain. 1983;17:1.33-44.

14. Lefebvre JC, Lester N, Keefe FJ. Pain in young adults. II: The use and perceived effectiveness of pain-coping strategies. Clin J Pain. 1995;11:1. 36-44. 15. Robinson ME, Riley JL 3rd, Myers CD, et al. The Coping Strategies Questionnaire: a large sample, item level factor analysis. Clin J Pain. 1997;13:1. 43-9.

16. Shimizu H, Murayama A, Daibo I. Analyzing 
the interdependence of group communication (1) -Application of hierarchical analysis into communication data-. IEICE Technical Report. 2006;106:146. 1-6(in Japanese with English abstract).

17. Ohtori S, Ito T, Yamashita M, et al. Evaluation of low back pain using the Japanese Orthopaedic Association Back Pain Evaluation Questionnaire for lumbar spinal disease in a multicenter study: differences in scores based on age, sex, and type of disease. J Orthop Sci. 2010;15:1. 86-91. DOI: 10.1007/ s00776-009-1426-8.

18. Higuchi D: Does perceived control over pain modify associations among pain, coping strategies, and psychological status in preoperative painful patients with compressive cervical myelopathy? J Spine Res. 2015;6:9. 1392-9.

19. Toomey TC, Mann JD, Abashian S. ThompsonPope S. Relationship between perceived self-control of pain, pain description and functioning. Pain. 1991;45:2. 129-33.

20. Woby SR, Watson PJ, Roach NK, Urmston M. Coping strategy use: does it predict adjustment to chronic back pain after controlling for catastrophic thinking and self-efficacy for pain control? J Rehabil Med. 2005;37:2. 100-7.

21. Sinikallio S, Aalto T, Airaksinen O, et al. Depression and associated factors in patients with lumbar spinal stenosis. Disabil Rehabil. 2007;28:7.

$415-22$.

22. Silverplats K, Lind B, Zoëga B, et al. Clinical factors of importance for outcome after lumbar disc herniation surgery: long-term follow-up. Eur Spine J. 2010;19:9. 1459-67. DOI: 10.1007/

s00586-010-1433-7.
23. Johansson AC, Linton SJ, Rosenblad A, Bergkvist L, Nilsson O. A prospective study of cognitive behavioural factors as predictors of pain, disability and quality of life one year after lumbar disc surgery. Disabil Rehabil. 2010;32:7. 521-9. DOI: 10.3109/09638280903177243.

24. Wolter T, Fauler I, Kieselbach K. The impact of psychological factors on outcomes for spinal cord stimulation: an analysis with long-term follow-up. Pain Physician. 2013;16:3. 265-75.

25. Morsø L, Kent PM, Albert HB. Are selfreported pain characteristics, classified using the PainDETECT questionnaire, predictive of outcome in people with low back pain and associated leg pain? Clin J Pain. 2011;27:6. 535-41. DOI: 10.1097/ AJP.0b013e318208c941.

\section{Disclosures \& COI}

The author reports no conflicts of interest.

\section{Corresponding Author}

Dasuke Higuchi, Department of Physical Therapy, Faculty of Health Care, Takasaki University of Health and Welfare 501 Nakaohrui, Tasakaki, Gunma 370-0033, Japan

Published 20 May 2016.

This manuscript is generously published free of charge by ISASS, the International Society for the Advancement of Spine Surgery. Copyright ๑ 2016 ISASS. To see more or order reprints or permissions, see http://ijssurgery.com. 